\title{
Editorial: An Ecological Perspective on Decision-Making: Empirical and Theoretical Studies in Natural and Natural-Like Environments
}

\author{
Ahmed El Hady ${ }^{1,2}$, Jacob D. Davidson ${ }^{3,4 *}$ and Deborah M. Gordon ${ }^{5}$ \\ ${ }^{1}$ Princeton Neuroscience Institute, Princeton University, Princeton, NJ, United States, ${ }^{2}$ Howard Hughes Medical Institute, \\ New York, NY, United States, ${ }^{3}$ Department of Collective Behaviour, Max Planck Institute of Animal Behaviour, Radolfzell, \\ Germany, ${ }^{4}$ Department of Biology, Universität Konstanz, Konstanz, Germany, ${ }^{5}$ Department of Biology, Stanford University, \\ Stanford, CA, United States
}

Keywords: decision-making, neuroscience, natural behavior, ecology, state-dependence, agent based modeling

\author{
Editorial on the Research Topic
}

An Ecological Perspective on Decision-Making: Empirical and Theoretical Studies in Natural and Natural-Like Environments

The processes that neuroscientists study, including sensory systems, cognitive capabilities, and decision-making, depend on ecological and evolutionary forces that shape how animals adapt to environmental change. This raises fundamental questions both in neuroscience and in evolutionary

\section{OPEN ACCESS}

Edited and reviewed by: Jordi Figuerola,

Estación Biológica de Doñana $(E B D)$, Spain

${ }^{*}$ Correspondence: Jacob D. Davidson

jdavidson@ab.mpg.de

Specialty section:

This article was submitted to Behavioral and Evolutionary Ecology,

a section of the journal

Frontiers in Ecology and Evolution

Received: 14 October 2019 Accepted: 18 September 2019 Published: 03 December 2019

Citation:

El Hady A, Davidson JD and Gordon DM (2019) Editorial: An

Ecological Perspective on

Decision-Making: Empirical and

Theoretical Studies in Natural and

Natural-Like Environments.

Front. Ecol. Evol. 7:461.

doi: 10.3389/fevo.2019.00461 biology. In systems neuroscience, decision-making has usually been studied by training animals to perform stereotyped behavior in laboratory conditions (Gold and Shadlen, 2007; Shadlen and Kiani, 2013; Hanks and Summerfield, 2017). This has helped to elucidate the neurobiological mechanisms of decision-making, but does not describe how such decisions are performed in a natural environment, and what are the ecological and evolutionary forces that shaped these processes (Krakauer et al., 2017; Mobbs et al., 2018). It remains an open question whether the neural mechanisms for trained behavior are recruited for decisions made in natural settings. On the other hand, behavioral ecology examines the evolutionary pressures that lead to decisions that function in natural environments (Krebs and Davies, 1997). This approach generally does not examine the cognitive machinery that processes information, leaving open the question how neural processing systems constrain decision-making.

Recent advances in data acquisition technology, computer vision, behavioral modeling, and machine learning facilitate the collection and efficient processing of data on behavior and environmental details (Berman, 2018; Brown and Bivort, 2018), and also enable neural recordings from freely moving animals (Kerr and Nimmerjahn, 2012; Jun et al., 2017). The perspectives of both systems neuroscience and behavioral ecology are needed in order to use such data to form a deeper mechanistic understanding of decision-making (Bateson and Laland, 2013; Nesse, 2013). The articles in this special issue provide theoretical frameworks and case studies that highlight the crucial importance of connecting ecological context to the study of decision making. Two review articles discuss challenges, open questions, and theoretical frameworks related to incorporating ecological context and cognitive processes into studies on decision-making (DeAngelis and Diaz), Budaev et al.. Three research articles provide examples across a range of species-ants, caterpillars, and primates-for how both lab and field experiments can be used to study natural decisions (Despland), how environmental context affects evolution of sensory processing systems (Ogawa et al.), and how environment conditions can affect the information used to make decisions (Janson). 
A challenge in designing laboratory experiments is to capture the key elements of the decisions that animals make in their natural environment. Despland combined field observations with lab experiments to study aggregation behavior of caterpillars and their decisions when to initiate feeding on leaves. The results show that when a caterpillar decides to feed, a behavior which influences its survival, depends both on social context and environmental factors including the trichome defenses of the plant.

Natural environments present many sensory stimuli that can combine to influence decision-making. Budaev et al. discuss the influence of state-dependence and the need to filter relevant sensory information, such as hunger or fear, on decisions made in a complex environment. In the framework they present, an animal's state sets the priority for each decision system, such as nutrition or survival, and top-down attention mechanisms regulate and limit which sensory information is processed.

Filtering of information can also be selected for, leading to animals with sensory systems that are adapted to their environment, as demonstrated in the case of ants in the article by Ogawa et al. This study examines two closely related ant species and show that they have optimized their visual system differently in order to adapt to their respective visual ecology.

Janson demonstrates that environmental conditions and individual capabilities influence the relative benefit of additional information and cognitive processes, such as memory, in decision-making (e.g., memory). Inspired by the results of field

\section{REFERENCES}

Bateson, P., and Laland, K. N. (2013). Tinbergen's four questions: an appreciation and an update. Trends Ecol. Evol. 28, 712-718. doi: 10.1016/j.tree.2013.09.013

Berman, G. J. (2018). Measuring behavior across scales. BMC Biol. 16:23. doi: 10.1186/s12915-018-0494-7

Brown, A. E. X. and de Bivort, B. (2018). Ethology as a physical science. Nat. Phys. 14, 653-657. doi: 10.1038/s41567-018-0093-0

Gold, J. I., and Shadlen, M. N. (2007). The neural basis of decision making. Annu. Rev. Neurosci. 30, 535-574. doi: 10.1146/annurev.neuro.29.051605.113038

Hanks, T. D., and Summerfield, C. (2017). Perceptual decision making in rodents, monkeys, and humans. Neuron 93, 15-31. doi: 10.1016/j.neuron.2016.12.003

Jun, J. J., Steinmetz, N. A., Siegle, J. H., Denman, D. J., Bauza, M., Barbarits, B., et al. (2017). Fully integrated silicon probes for high-density recording of neural activity. Nature 551:232. doi: 10.1038/nature24636

Kerr, J. N., and Nimmerjahn, A. (2012). Functional imaging in freely moving animals. Curr. Opin. Neurobiol. 22, 45-53. doi: 10.1016/j.conb.2011. 12.002

Krakauer, J. W., Ghazanfar, A. A., Gomez-Marin, A., MacIver, M. A., and Poeppel, D. (2017). Neuroscience needs behavior: correcting a reductionist bias. Neuron 93, 480-490. doi: 10.1016/j.neuron.2016.12.041 experiments on wild capuchin monkeys, they simulate foraging decisions and ask how including memory of elapsed time since prior foraging visits improves foraging efficiency in different resource environments.

DeAngelis and Diaz highlight the importance of including individuals' decision making strategies into population level ecological models, and discuss how agent-based models can be used to examine the fitness consequences of specific individual decision rules. For example, agent based modeling can represent differences between individuals in a population or co-dependent strategies such as predator-prey interactions, and opens up the opportunity to provide mechanistic interpretations for long standing population level ecological phenomena.

We hope these articles inspire further work that combines systems neuroscience and behavioral ecology.

\section{AUTHOR CONTRIBUTIONS}

All authors listed have made a substantial, direct and intellectual contribution to the work, and approved it for publication.

\section{FUNDING}

JD acknowledges partial support by the DFG Centre of Excellence 2117 Centre for the Advanced Study of Collective Behaviour (ID: 422037984). AE is supported by Howard Hughes Medical Institute (HHMI).

Krebs, J. R., and Davies, N. B. (eds.). (1997). Behavioural Ecology: An Evolutionary Approach. 4th ed. Cambridge, MA: Wiley-Blackwell.

Mobbs, D., Trimmer, P. C., Blumstein, D. T., and Dayan, P. (2018). Foraging for foundations in decision neuroscience: insights from ethology. Nat. Rev. Neurosci. 19:419. doi: 10.1038/s41583-018-0010-7

Nesse, R. M. (2013). Tinbergen's four questions, organized: a response to bateson and laland. Trends Ecol. Evol. 28, 681-82. doi: 10.1016/j.tree.2013.10.008

Shadlen, M. N., and Kiani, R. (2013). Decision making as a window on cognition. Neuron 80, 791-806. doi: 10.1016/j.neuron.2013.10.047

Conflict of Interest: The authors declare that the research was conducted in the absence of any commercial or financial relationships that could be construed as a potential conflict of interest.

Copyright $\odot 2019$ El Hady, Davidson and Gordon. This is an open-access article distributed under the terms of the Creative Commons Attribution License (CC BY). The use, distribution or reproduction in other forums is permitted, provided the original author(s) and the copyright owner(s) are credited and that the original publication in this journal is cited, in accordance with accepted academic practice. No use, distribution or reproduction is permitted which does not comply with these terms. 